\title{
Unlocking the Secrets of Morphosyntactic Development by Examining Acquisition Order Disparities in an EFL Context
}

\author{
Andrew D. Schenck, Wonkyung Choi* \\ English Education, Department of Liberal Arts Education (LAEC), Ju Si-gyeong College, Pai Chai University, \\ Daejeon, South Korea \\ Email: Schenck@hotmail.com, *wkchoi@pcu.ac.kr
}

Received November 18 $8^{\text {th }}, 2012$; revised December 18 $8^{\text {th }}, 2012$; accepted December $25^{\text {th }}, 2012$

\begin{abstract}
This study examined acquisition order disparities and their associated causes in an EFL context, so that pedagogical means of enhancing the process of morphosyntactic development could be discovered. Twenty-six South Korean EFL middle school students were given an extensive timed writing test. Following the administration of this test, an acquisition order for 16 morphosyntactic features was constructed. The EFL order was first compared to others found in ESL contexts. It was then compared to six hypothesized causes of acquisition: EFL input frequency, L1 similarity, morphosyntactic variability, semantic complexity, sonority, and morphosyntactic complexity. Results suggest that while input frequency and L1 similarity are the most significant predictors, all causal variables have a role in the manifestation of acquisition order within an EFL context. Suggestions for curricular reform that utilize the unique causal characteristics of each morphosyntactic feature have been proposed.
\end{abstract}

Keywords: Acquisition; Morphosyntactic Features; L1 Transfer; Sonority; EFL Input; Korean

\section{Introduction}

In the fall of 1962, Brown's (1973) longitudinal study of three preschool children identified a process of morphosyntactic development whereby L1 English learners acquire the same 14 morphological features in a distinct order. Features such as the present progressive, prepositions (in and on), plural -s, past irregular tenses, and possessive 's appeared early in the language development process, while features such as the thirdperson singular $-s$ and contracted verb forms (the copula and auxiliary) appeared late (Brown, 1973).

Following the discovery of this "invariant" order of grammatical development for L1 learners, Dulay and Burt (1973, 1974 , 1975) further found that young ESL learners acquire morphological features in a distinct order. The progressive -ing and plural $-s$ morphemes, for example, tended to be acquired early, while the third person singular -s morpheme was usually acquired late in the language learning process. In contrast to the L1 acquisition process, features such as the past irregular tense and possessive 's were acquired late within ESL sequences of grammatical development, while contractible forms of the copula and auxiliary were acquired earlier (Dulay and Burt, 1973). Despite key differences in the L1 and L2 acquisition orders, Dulay and Burt (1974) came to the conclusion that a universal cognitive process governed the acquisition of grammatical features. Subsequent research also adopted this paradigm, declareing that acquisition order was common for ESL learners of all ages and linguistic backgrounds (Dulay \& Burt, 1974; Krashen, Butler, Birnbaum, \& Robertson, 1978; Dulay, Burt, \& Krashen, 1982; Pienemann, Di Biase, \& Kawaguchi, 2005).

In the 1980 's, researchers began to develop stage-by-stage analyses of the hypothesized "universal" orders of morphosyntactic development. Krashen and Terrell (1983), for example,

${ }^{*}$ Corresponding author. through the synthesis of several past studies, developed a 4stage hierarchy of morphosyntactic development termed the Natural Order (Appendix A). According to this order, progressive, copula, and plural morphemes were acquired in early stages, while the past tense, third person singular, and possessive morphemes were acquired late. Following the Natural Order Hypothesis, researchers such as Pienemann (1995, 1999, $2005,2008)$ and Johnston $(1985,1994)$ used research to develop a six stage process of morphosyntactic development called the Processability Model (Appendix A). Unlike prior research of morphological features, the Processability Model included several syntactic features involved in the creation of question construction and complex clauses. Grammatical features were organized into six discreet categories, which revealed the development of speech from small phrases to complex sentences and questions (Dyson, 2008; Dyson, 2009).

Because research traditionally emphasized the universality of grammatical acquisition, explicit grammar instruction has relied heavily on general-purpose frameworks designed to introduce features at a cognitively opportune time (Chamot, 2009; Echevarria, Vogt, \& Short, 2008; Fotos, 2001). Pedagogical practices such as the Teachability Hypothesis and I + 1 theory, for example, which were developed for the Processability Model and the Natural Order Hypothesis, respectively, advocate the presentation of morphosyntactic features that are slightly more difficult than a learner's developmental level (Pienemann, 2005; Yang, 2008). While such frameworks have been shown to be effective within a clinical setting, research suggests that their adaptation to practice has been limited (Schenck \& Lee, 2009; Spada \& Tomita, 2010).

In reality, the limited utilization of general-purpose frameworks based upon acquisition order research appears to be caused by a significant deficiency in understanding of morphosyntactic development. Educators are now unable to concretely 
connect acquisition order to practice because the process is still not fully understood. Since past research heavily emphasized universality over disparity (Mitchell \& Myles, 2004), key differences of morphosyntactic sequences, which may have been caused by factors such as L1 transfer and differential input frequency, were largely ignored (Luk \& Shirai, 2009). Research now suggests that even well-established acquisition sequences, such as Brown's (1973) 14-morpheme acquisition order, may differ significantly based upon contextual factors (James \& Khan, 1982).

Due to the recognition of fundamental disparities in acquisition order, researchers have begun to more heavily investigate the impact of external stimuli such as input frequency on the emergence of grammar in speech and writing (Ellis, 2002; Ellis \& Collins, 2009; Nekrasova, 2009). This research has illuminated some processes of acquisition, but the manifestation of grammatical order is still not fully understood. Additional studies that holistically document the interaction of multiple influences, to include both input frequency and L1 transfer, are now required to provide a more holistic understanding of morphosyntactic development. This understanding may provide essential information needed to reform and improve explicit grammar curricula.

\section{Acquisition Order Disparities in an EFL Context}

Early research concluded that EFL acquisition order was virtually the same as that found within ESL contexts (Dulay, Burt, \& Krashen, 1982). A study by Makino (1979), for example, which examined the acquisition order of 777 Japanese EFL secondary school students, found that EFL learners acquired features in stages that were nearly equivalent to their ESL peers. Since the progressive, copula, and plural were relatively easier to acquire, while the third person singular, past regular tense, and past irregular tense were more difficult to acquire, Makino (1979) concluded that acquisition orders were similar for children, adolescents, and adults, even if the surrounding environmental conditions differed. This finding led researchers such as Dulay, Burt, and Krashen (1982) to conclude that one universal cognitive force was responsible for the apparently ubiquitous morphosyntactic sequence.

Although the EFL order obtained by Makino's (1979) study did, indeed, reveal similarities to those obtained from ESL contexts, there were key differences. Because the research was highly focused upon uncovering universal processes of morphosyntactic development, disparities were unexplored or overlooked. In reality, three of the nine features examined within the study emerged in a disparate order; the sequential positions of the possessive, article, and progressive auxiliary morphemes, for example, were different from those obtained by Dulay and Burt's (1974) study. Despite the presence of significant differences in acquisition order, the preoccupation with an "invariant order" continued to inhibit the identification of variance and associated causes.

To address shortcomings with past research, a recent review of SLA research by Luk and Shirai (2009) identified key discrepancies in the acquisition of the article, plural -s, and possessive 's features among Asian learners from Japan, China, and Korea. Articles and plural $-s$ morphemes were cited to be acquired later than predicted by the Natural order, whereas the possessive 's morpheme was acquired earlier. These anomalies were explained through examining the congruency and mor- phological similarity of the features in the L1 and L2. The study found that the possessive morpheme was linguistically congruent and shared the bound morphological attribute in all languages examined, explaining the early emergence of this feature. The article and plural morphemes, in contrast, were not considered to be congruent, explaining the late emergence (Luk \& Shirai, 2009).

While the study by Luk and Shirai (2009) was a step forward, it failed to comprehensively examine other factors that impact acquisition, such as phonological salience, morphosyntactic variability, morphosyntactic complexity, semantic complexity, and input frequency. As revealed by studies of ESL contexts (Goldschneider \& DeKeyser, 2005; Schenck \& Choi, 2012), the concomitant consideration of these multiple causal factors may facilitate the development of a more holistic view of acquisition and its associated causes. The purpose of this study, therefore, is to comprehensively examine the influence of multiple factors of acquisition in an EFL context. Because variables such as input frequency vary within EFL contexts such as South Korea (Goh, 2007; Kim, 2002), results of study within these environments may allow for the understanding of how causal manipulation will impact the acquisition process. Ultimately, this understanding is a prerequisite of curricular reform, since educators must know what changes are required before a desired result can be engineered.

\section{Research Questions}

Although studies demonstrate a means to explain acquisition order through collective analysis of causes such as phonological salience, frequency, morphological variability, semantic complexity, and syntactic complexity (Goldschneider \& DeKeyser, 2005; Schenck \& Choi, 2012), exclusive research in an ESL context has restricted understanding of how differential causal values (e.g., EFL frequency and L1 transfer) can affect acquisition order. To address this deficiency within research, the current study was developed to holistically examine acquisition and associated causes within an EFL context. The following questions were posed:

Q1. How does EFL acquisition order compare to that found within ESL contexts?

A. In what order do South Korean EFL learners acquire morphosyntactic features?

B. How is the EFL acquisition order similar to those found in ESL contexts? How is it different?

Q2. Why does EFL acquisition order differ from that found within ESL contexts?

A. To what degree is the resulting South Korean EFL acquisition order explained by individually considering variables such as frequency, phonological salience, morphosyntactic variability, syntactic complexity, semantic complexity, and L1 transfer of each morphosyntactic feature?

B. To what degree is the resulting South Korean EFL acquisition order explained by cumulatively considering frequency, phonological salience, morphosyntactic variability, syntactic complexity, semantic complexity, and L1 transfer of each morphosyntactic feature?

Question one was selected to examine the effects of an EFL environment on the acquisition phenomenon. Question two aims to explain why the differences between acquisition orders occur. 


\section{Research Methods and Design}

The present study, which was conducted in a South Korean EFL context, investigated the same 16 grammatical features previously examined within an ESL environment (Schenck \& Choi, 2012). This form of analysis allowed for the cross-contextual comparison of acquisition orders and associated variables (e.g., input frequency), thereby facilitating the development of a more holistic perspective.

\section{Participants}

To provide a sample for the study of EFL acquisition, 26 middle school learners were selected from a population at a South Korean middle school. Students who did not have native-speaking tutors and hadn't studied abroad were purposively selected using snowball sampling. Because the selected sample had had less exposure to English communicative input outside the classroom, morphosyntactic frequency values obtained from public school input, used as one predictor of morphosyntactic acquisition order, were thought to have heightened validity (Schenck, 2012).

Although participants did not have extensive experience with native speakers, most of the participants did have experience attending extracurricular English academies. Only four had not attended any English academies. The remainder of participants had a mean average of 4.33 years attending private academies, attending classes from two to three times a week for about one hour. All students were either in their first or second year of middle school and ranged in age from 11 to 15 years old.

\section{Instrument and Materials}

Each student was given a writing activity (See Appendix C) which included tasks designed to provide at least three communicative contexts for each of the 16 morphosyntactic features studied (Appendix B). The test was administered orally, and students were given 30 seconds for each response. The responses were timed to reduce the chance that they were edited or reviewed after creation. As revealed in a study by Ellis (2005), giving tests with timing tends to elicit implicit, rather than explicit knowledge of grammatical features. Since research has confirmed a clear link between the sequence of morphosyntactic acquisition in both speaking and writing (Dulay, Burt, \& Krashen, 1982), written responses were also considered to be a valid indicator of morphosyntactic competence.

In addition to questions created by the researcher, communicative tasks from the syntax component of the Comprehensive Assessment of Spoken English (CASL) were used to ensure that more than three contexts were provided for each morphosyntactic feature. The CASL includes a series of pictures that provide natural communicative contexts for the use of multiple morphosyntactic features (Carrow-Woolfolk, 1999).

Throughout the delivery of all communicative exercises, participants were encouraged to use their creativity, without fear of being graded or reprimanded. This helped to ensure that a playit-safe strategy, which would limit the number of morphosyntactic features represented in the resulting data, was not employed.

\section{Operational Definition of Variables}

Acquisition Level. Acquisition level refers to the degree to which a morphosyntactic feature is correctly used in communicative contexts where the feature is required. This ratio scale variable was determined in two steps. First, point values were assigned to morphosyntactic features within the written data according to the following system developed by Dulay, Burt, \& Krashen (1982):
1) Correct morpheme
2) Misformed morpheme
3) Incorrect/Absent morpheme
2 points ("sat");
1 point ("sitted");
0 points ("sit").

Second, a percentage of proficiency was calculated by adding all the points for correct and misformed responses, and dividing this number by the total of obligatory contexts multiplied by two (Dulay, Burt, \& Krashen, 1982).

Frequency. Frequency refers to the number of times a morphosyntactic feature is present within input communicated to the learner. This ratio scale variable was obtained from a study of elementary school EFL input (Schenck, 2012). The study includes all the elementary school English input that was received by the Korean middle school participants from grades 1 to 6. The frequency values are based upon the content of a strictly regimented national curriculum that was administered to all elementary students in South Korea, including those examined within this study.

L1 Similarity. L1 similarity refers to the degree to which a learner's native language resembles English. This degree of similarity was calculated using the method employed by Luk \& Shirai (2009). It used two characteristics for cross-linguistic comparison of morphosyntactic features: presence/absence of the feature and the free/bound/lexical attribute. If any of the characteristics were positive for a similarity, they were assigned the value of 1 . The scores for each characteristic were then added to get a final score for similarity (maximum value of 2). When considering past irregular tense, for example, a final value of 2 was assigned, since the Korean language has the same lexically altered feature. To determine similarity for question inversion, the auxiliary verb was considered. If the auxiliary verb was present in Korean, a value of 1 was assigned. If it had the same free/bound/lexical attribute as in English, it was also assigned a value of 1 . Although inversion of the auxiliary was also considered, the absence of this feature in Korean indicated that no additional value could be added, making the maximum similarity values for these features 2 .

Morphosyntactic variability. Morphosyntactic variability is a ratio scale variable that refers to the number of different forms a grammatical feature may take. Values for each morphosyntactic feature were calculated by determining the number of alternations each feature had (e.g., the number of allomorphs or syntactic variants) according to a method used within a prior study of ESL acquisition (Schenck \& Choi, 2012).

Phonological salience. Phonological salience refers to the ease with which a morphosyntactic feature can be heard (Goldschneider and DeKeyser, 2005). This ratio scale variable was calculated by determining a feature's sonority, which is the degree to which the vocal tract is open during articulation (Yavas, 2010). Sonority was determined by using a scale employed within a prior study of ESL acquisition (Schenck \& Choi, 2012).

Semantic complexity. Semantic complexity is a ratio scale variable that refers to the total number of meanings conveyed by a morphosyntactic feature (Goldschneider \& DeKeyser, 2005). To calculate semantic complexity, the number of meanings conveyed for each grammatical structure were added using a 
method devised by Brown (1973) and later expanded for syntactic features (Schenck \& Choi, 2012).

Morphosyntactic complexity. Morphosyntactic complexity refers to the degree of difficulty learners have acquiring a new grammatical feature. A value for this variable was empirically assigned using a method employed within a prior study (Schenck $\&$ Choi, 2012). Features were categorized based upon an ordinal scale that ranged from 6 (the least complex) to 1 (the most complex). The scale was based on the Processability Model, which suggests that less complex intra-phrasal aspects of morphology are acquired first, followed by more complex interphrasal and inter-sentential aspects of syntax (Pienemann, 1999).

\section{Data Collection, Processing, and Analysis}

\section{Research Question One}

Question one was investigated through a two-step process. First, the sequence of acquisition was constructed using the data collected from the South Korean EFL participants. To determine the acquisition percentage for each grammatical feature, written data was cross-referenced with its corresponding suppliance in obligatory context (SOC), which refers to the context where a particular morphosyntactic feature must be used. The use of the SOC has been criticized by some researchers such as Bley-Vroman (1983), because it does not identify the true nature of interlanguage development, and does not empirically evaluate factors such as oversuppliance of a morphosyntactic feature. Despite such problems, use of the SOC is still recognized as providing one universal "yardstick" for the measurement of grammatical accuracy (Kwon, 2004).

Instead of calculating acquisition percentages by averaging responses for the group as a whole, averages of grammatical accuracy were first determined for each individual participant. The resulting percentages were then averaged again to get a final group percentage for the acquisition of each feature. This method mitigated the possibility of skewing from either oversuppliance or undersuppliance of a morphosyntactic feature by individual participants, which is cited as a potential problem by Dulay, Burt, and Krashen (1982).

After acquisition percentages for the group were calculated and ranked, the resulting EFL sequence was statistically compared to both the Natural Order and Processability Theory using the Spearman rank correlation formula. Differences in acquisition which influenced the correlation values were then qualitatively analyzed to identify notable disparities in the South Korean EFL sequence.

\section{Research Question Two}

To assess the influence of multiple factors on morphosyntactic development, various causes of acquisition order were compared to the grammatical sequence obtained from South Korean EFL participants. Ratings for each independent variable (frequency, phonological salience, morphosyntactic variability, semantic complexity, and syntactic complexity) were first compared to acquisition order separately using the Spearman rank correlation formula. Correlations were then examined to assess causal impact on the acquisition process.

After individual correlations were calculated and analyzed, multiple linear regression was used to assess the collective influence of causes on the acquisition process. Results were analyzed to determine the degree to which concomitant factors influence morphosyntactic development.

\section{Results and Discussion}

After acquisition percentages for each grammatical feature were calculated and ranked, the sequence of morphosyntactic development in Table 1 was revealed.

According to the EFL order in Table 1, morphological features such as negation, the copula, the progressive, and the plural emerge early, within the first half of the sequence. Syntactic features such as do, Wh copula, and yes/no auxiliary inversion also appear early in the acquisition order. In contrast, morphological features such as the past irregular, past regular, article, and third person singular emerge within the second half of the order. Syntactic features, likewise, such as Wh auxiliary question inversion and cancel inversion emerge late in the sequence. Phrasal verb separation was completely absent from the participants' writings. Thus, it was placed at the end of the sequence.

Comparison of the EFL acquisition order to those found in ESL contexts, namely, the Natural Order and the Processability Model, revealed several similarities and some notable differences. Empirical correlation revealed significant results which are shown in Table 2.

The EFL acquisition order significantly correlated to both the Processability Model and the Natural Order Hypothesis, yielding values of $r_{s}=.699(p=.036)$ and $r_{s}=.778(p=.014)$, respectively. Although sequences correlated highly, there were distinct differences. Within the South Korean EFL acquisition order, acquisition percentages reveal that verbal negation emerged earlier than the plural $-s$ feature. This contrasts with the Processability Model, which hypothesizes that an initial form of verbal negation will emerge in stage three, while the plural -s feature is posited to emerge in stage two. The EFL acquisition order also revealed a disparity with the emergence of the phrasal verb. This feature did not appear in the students' written data, despite the Processability Model's hypothesis that it will emerge in stage four, before Wh auxiliary question inversion, the third person singular, and cancel inversion. Forms of question inversion appeared to adhere to the order outlined by the Processability Model.

Table 1.

Acquisition order in a South Korean EFL context.

\begin{tabular}{lc}
\hline \multicolumn{1}{c}{ Grammatical Feature } & Acquisition Percentage \\
\hline 1) Verbal negation & 97.44 \\
2) Copula & 91.96 \\
3) Progressive auxiliary total & 85.45 \\
4) Plural -s & 85.24 \\
5) Do question inversion & 84.42 \\
6) Wh copula question inversion & 77.05 \\
7) Yes/no auxiliary question inversion & 77.04 \\
8) Progressive -ing & 74.97 \\
9) Past irregular & 72.60 \\
10) Possessive 's & 63.27 \\
11) Article & 62.36 \\
12) Third person singular -s & 57.79 \\
13) Wh auxiliary question inversion & 38.53 \\
14) Past regular & 32.69 \\
15) Cancel inversion & 5.77 \\
16) Phrasal verb separation & .0 \\
\hline
\end{tabular}


Other disparities existed between the EFL acquisition percentages and the Natural Order. First, the progressive auxiliary morpheme appeared earlier in the EFL acquisition order, emerging between the copula and plural $-s$ feature. This contrasts with the Natural Order, which hypothesizes that the progressive auxiliary emerges in stage two, while the copula and plural $-s$ morphemes appear in stage one. A second major disparity is the emergence of the article. Within the EFL acquisition order, it appears between the possessive 's and third person singular, both of which are hypothesized to emerge during stage four in the Natural Order. Within the Natural Order, however, the article is hypothesized to emerge two stages earlier than these features, in stage two.

Table 2.

Spearman rank correlations of Korean EFL acquisition order to the Processability Model and Natural Order Hypothesis.

\begin{tabular}{ccc}
\hline & Processability Model & Natural Order Hypothesis \\
\hline Pearson Correlation & $.699^{*}$ & $.778^{*}$ \\
Sig. (2-tailed) & .036 & .014 \\
$\mathrm{~N}$ & 9 & 9 \\
\hline
\end{tabular}

"Correlation is significant at the .05 level (2-tailed).
Through analysis of various causes of acquisition order, reasons for notable differences of grammatical sequences may be revealed. Correlations of EFL acquisition percentages for each grammatical feature to six causes (Frequency, L1 Similarity, Morphosyntactic Variability, Morphosyntactic Complexity, Semantic Complexity, and Sonority) using the Spearman rank correlation formula yielded interesting results (Table 3).

Results of Table 3 reveal a strong correlation of acquisition rates to causal variables such as input frequency $\left(r_{s}=.699 ; p\right.$ $=.003)$ and L1 similarity $\left(r_{s}=.639 ; p=.008\right)$. This suggests that these two factors have a large impact on acquisition order in the EFL context. The significant correlations suggest that additional analysis of these two causes may explain fundamental differences in acquisition order. To illustrate, values of input frequency from both ESL and EFL contexts were converted to standardized $\mathrm{z}$ scores for comparison; the resulting $\mathrm{z}$ scores and values for L1 similarity were then listed alongside the acquisition order in Table 4.

Through viewing Table 4, reasons for the disparities in emergence of negation, the progressive auxiliary, the article, and the phrasal verb become more salient. Early emergence of the progressive auxiliary and negation in the EFL context may be partially explained through the analysis of L1 similarity.

Table 3.

Spearman rank correlations of EFL acquisition order to individual causes of acquisition.

\begin{tabular}{ccccccc}
\hline & Frequency in EFL Context & L1 Similarity & Morphosyntactic Alternations & Semantic Complexity & Sonority & Morphosyntactic Complexity \\
\hline $\begin{array}{c}\text { Correlation } \\
\text { Coefficient }\end{array}$ & $.699^{* *}$ & $.639^{* *}$ & -.369 & -.392 & -.202 & -.466 \\
Sig. (2-tailed) & .003 & .008 & .159 & .133 & .452 & .069 \\
$\mathrm{~N}$ & 16 & 16 & 16 & 16 & 16 & 16 \\
\hline
\end{tabular}

${ }^{* *}$ Correlation is significant at the .01 level (2-tailed).

Table 4.

Comparison of acquisition order to the Korean L1, frequency in an EFL context, and frequency in and ESL context.

\begin{tabular}{lccc}
\hline \multicolumn{1}{c}{ EFL Acquisition Order } & $\begin{array}{c}\text { L1 Similarity } \\
\text { (Korean) }\end{array}$ & Frequency in EFL Context (z Scores) & $\begin{array}{c}\text { Frequency in ESL Context (z Scores) } \\
\text { (Schenck \& Choi, 2012) }\end{array}$ \\
\hline 1) Verbal negation & 2 & -.0784 & -.2101 \\
2) Copula & 2 & 3.4090 & -.0882 \\
3) Progressive auxiliary & 2 & -.3091 & -.4233 \\
4) Plural -s & 2 & .0873 & .3451 \\
5) Do question inversion & 1 & -.3919 & -.5023 \\
6) Wh copula question inversion & 2 & .5546 & -.5011 \\
7) Yes/no auxiliary question inversion & 1 & -.0458 & -.4913 \\
8) Progressive -ing & 2 & -.3091 & -.0244 \\
9) Past irregular & 1 & -.5014 & .7214 \\
10) Possessive 's & 2 & -.5605 & -.4327 \\
11) Article & 0 & .8149 & 3.5148 \\
12) Third person singular -s & 0 & -.5309 & -.1789 \\
13) Wh auxiliary question inversion & 1 & -.3387 & -.5048 \\
14) Past regular & 2 & -.5457 & -.2149 \\
15) Cancel inversion & 0 & -.6286 & -.5097 \\
16) Phrasal verb separation & 0 & -.6256 & -.4997 \\
\hline
\end{tabular}


First of all, the progressive auxiliary and verbal negation are both morphologically similar in Korean. Negation is achieved in Korean by adding a morphological structure to the end of a verb, as in contracted forms of the auxiliary in English (e.g., $d o n ' t$, isn't). Not surprisingly, nearly all negation (with the exception of one instance, is not) utilized the contracted forms of negation, such as don't, didn't, won't, can't, and isn't, which are highly congruent with the Korean language. The progressive auxiliary, likewise, is similar in Korean. The feature uses an auxiliary verb that is a free morpheme in both languages.

While L1 similarity partially explains the early emergence of the progressive auxiliary and verbal negation, frequency also explains this phenomenon. Values of standardized $\mathrm{z}$ scores suggest that the proportion of input to which the Korean EFL participants were exposed was higher than that contained within an ESL context for both the progressive auxiliary and verbal negation (progressive: $-.3091>-.4233$; negation: $-.0784>$ $-.2101)$.

In addition to the progressive auxiliary and negation, the late emergence of the article and phrasal verb may be explained through combined analysis of L1 similarity and frequency. Unlike the progressive and negation, the article and phrasal verb are not present in the Korean language. Moreover, standardized $\mathrm{z}$ scores reveal that proportional use of the article and phrasal verb is lower within the South Korean EFL context (article: .8149<3.5148; phrasal verb: $-.6256<-.4997$ ).

The emergence of yet other grammatical features can be explained through the concomitant consideration of multiple causes, such L1 similarity and frequency. Most features that emerge within the first half of the EFL sequence, for example, such as the copula, plural, and progressive, tend to be present in the Korean language. Moreover, features within the first half of the EFL acquisition order, with the exception of the progressive -ing and do inversion, have the highest $\mathrm{z}$ scores, indicating that these features appear more often within input than those in the second half of the EFL acquisition order. Features such as the progressive -ing and do inversion, which do not appear to be as heavily influenced by factors such as L1 similarity and frequency, may be explained through considering the influence of other causes. These features have no alternate forms (e.g., do inversion within the Processability Model does not include tense) and are syntactically simple compared to other features that appear in the second half of the EFL acquisition order. In addition, these features are more highly sonorant, since they each have a vowel, than other features such as the plural $-s$, possessive 's, or third person singular $-s$.

In contrast to the features that emerge early within the EFL sequence, those that appear late tend to be absent from the Korean language (e.g., the article, third person singular, cancel inversion, and the phrasal verb). These features also tend to have a lower $z$ score within EFL input. With the exception of the article, all of the features to emerge in the second half of the South Korean sequence, from numbers 8 to 16 , have $\mathrm{z}$ scores lower than -.3 . Most have $\mathrm{z}$ scores lower than -.5 . The article, which frequently appears in the EFL input, albeit proportionately less so than within ESL input, has a high degree of semantic complexity, which explains its late emergence. Wh auxiliary inversion, which appears amid other features having $\mathrm{z}$ scores of -.5 and lower, had a larger $\mathrm{z}$ score of -.3 within the EFL input. Like the article, other factors can explain the late emergence of this feature, namely, the increasing levels of semantic complexity, morphosyntactic complexity, and alterna- tions introduced by the inversion of several different auxiliary verbs with different tenses.

While analysis of individual causes may explain some of the disparities of acquisition order, all six causes analyzed within this paper appear to synergistically influence the acquisition process. This idea was also exemplified by the results of multivariate empirical analysis. Multiple regression revealed a moderately high correlation value of $R=.77$ (Appendix D). According to the regression model, the six hypothesized independent variables explain nearly $60 \%$ of the morphosyntactic sequence. Moreover, the synthesis of these variables within the regression model yielded a higher significance value than individual causes alone $(p=.055)$. This suggests that multiple variables have a synergistic influence on the acquisition process. Overall, the results suggest that multiple causes do concomitantly exert some influence on acquisition order.

\section{Conclusion}

While results suggest that frequency and L1 Similarity are significant factors influencing acquisition in a South Korean EFL context, overall results of empirical and qualitative analysis indicate that all six hypothesized causes (frequency, L1 similarity, morphosyntactic complexity, semantic complexity, morphosyntactic variability, and phonological salience) synergistically contribute to the manifestation of acquisition order. Because all of the multiple causes appear to influence morphosyntactic development, it is imperative that educators adopt a new paradigm for the design of explicit grammar curricula. Most importantly, educators must deemphasize the one-sizefits-all strategy now commonly applied to grammar instruction, opting for reforms that provide activities tailored to the individual characteristics of each morphosyntactic feature. To further illustrate how this may be accomplished, values for the six causes of acquisition were ranked and compiled into charts for each grammatical feature. The ranking procedure resulted in the following chart for the plural morpheme, revealed in Figure 1.

Through observing the causal ranks of the plural morpheme, which are relative to the other sixteen grammatical features analyzed within this study, methods of tailoring instruction to individual characteristics of the target feature may be construed. First, the high frequency of the plural morpheme in an ESL context suggests that a large proportion of the input should include this feature to ensure that it is acquired. Since L1 differences are low, extensive translation and frequent explicit descriptions of the syntax may be unnecessary. The lower values for morphosyntactic variability, semantic complexity, and morphosyntactic complexity, likewise, suggest that means to emphasize these features, such as semantic maps, images, and grammar exercises, may not need to be used extensively. The difficulty hearing the plural morpheme (its low sonority) indicates that more extensive emphasis of the feature in listening input and pronunciation is required.

The ranking process yielded very different results for some features such as Wh auxiliary inversion, which is featured in Figure 2.

Unlike the plural feature, the Wh auxiliary question is not present within input as often. It, therefore, may not have to appear as frequently as other features within curricular input. Hearing difficulty is, likewise, low, suggesting that little emphasis within listening input may be needed. Since L1 differences, morphosyntactic variability, semantic complexity, and 




*Degree of Emphasis Required for Each Characteristic.

Figure 1.

Rank values for individual characteristics of the plural -s.

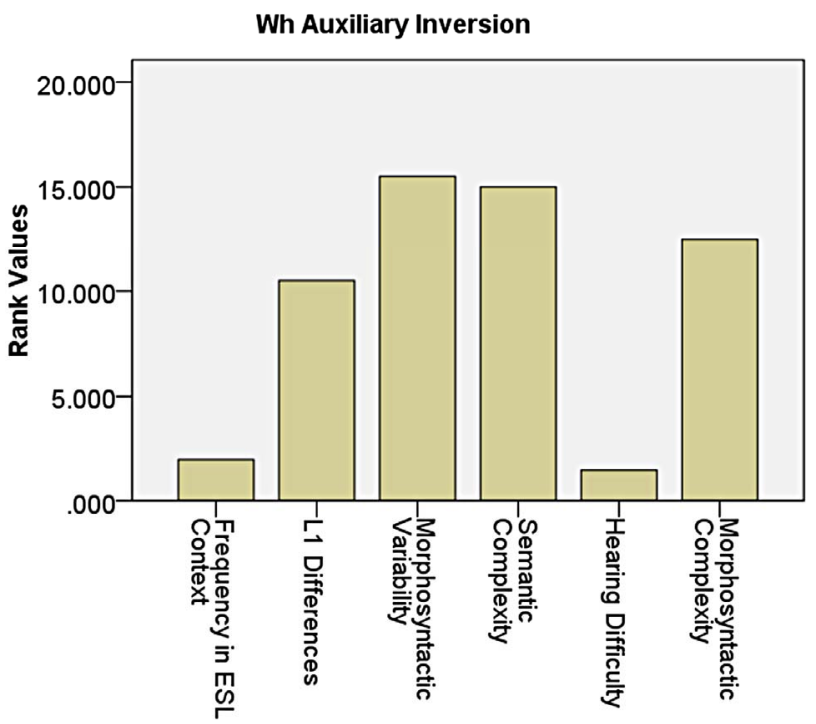

*Degree of Emphasis Required for Each Characteristic.

Figure 2.

Rank values for individual characteristics of Wh auxiliary inversion.

morphosyntactic complexity are all high, more emphasis on grammar activities, videos, semantic maps, and other activities that highlight structural and semantic differences will be needed. Speaking and writing activities should also compel students to examine differences in auxiliary type, tense, and associated contextual meanings.

In conclusion, causes such as frequency, L1 similarity, morphosyntactic complexity, semantic complexity, sonority, and morphosyntactic variability all appear to be influencing the acquisition process. It is essential that curriculum designers develop pedagogical techniques that utilize these causes. Since each grammatical feature has different characteristics, these disparities must also be utilized so that each morphosyntactic feature is uniformly acquired. Although results of this study are insightful, more research documenting the influences of multiple causes of acquisition order is needed. Moreover, the influ- ences of explicit grammar designs which tailor instruction to the characteristics of each grammatical feature must be further examined. Additional inquiries such as this will provide educators with the knowledge required to enhance grammar instruction for English learners.

\section{REFERENCES}

Bley-Vroman, R. (1983). The comparative fallacy in interlanguage studies: The case of systematicity. Language Learning, 33, 1-17. doi:10.1111/j.1467-1770.1983.tb00983.x

Brown, R. (1973). A first language. Cambridge, MA: Harvard University Press.

Carrow-Woolfolk, E. (1999). Comprehensive assessment of spoken language. Minneapolis, MN: Pearson, Inc.

Chamot, A. U. (2009). The CALLA handbook: Implementing the cognitive academic language learning approach. New York: Allyn \& Bacon.

Dulay, H. C., \& Burt, M. K. (1973). Should we teach children syntax? Language Learning, 23, 245-258. doi:10.1111/j.1467-1770.1973.tb00659.x

Dulay, H. C., \& Burt, M. K. (1974). Natural sequences in child language acquisition. Language Learning, 24, 37-53. doi:10.1111/j.1467-1770.1974.tb00234.x

Dulay, H. C., \& Burt, M. K. (1975). A new approach to discovering universals of child second language acquisition. In D. Dato (Ed.), Developmental psycholinguistics (monograph series on language and linguistics) (pp. 209-33). Washington, DC: Georgetown University Press.

Dulay, H. C., Burt, M. K., \& Krashen, S. (1982). Language two. New York: Oxford University Press.

Dyson, B. (2008). What we can learn from questions: ESL question development and its implications for language assessment. Prospect, 23, 16-27. doi: $10.1177 / 0267658309104578$

Dyson, B. (2009). Processability theory and the role of morphology in English as a second language development: A longitudinal study. Second Language Research, 25, 355-376.

Echevarria, J., Vogt, M. E., \& Short, D. J. (2008). Making content comprehensible for English learners: The SIOP Model. New York: Pearson.

Ellis, N. (2002). Frequency effects in language processing: A review with implications for theories of implicit and explicit language acquisition. Studies in Second Language Acquisition, 24, 143-188. doi:10.1017/S0272263102002024

Ellis, N., \& Collins, L. (2009). Input and second language acquisition: The roles of frequency, form, and function introduction to the special issue. The Modern Language Journal, 93, 329-335. doi:10.1111/j.1540-4781.2009.00893.x

Ellis, R. (2005). Measuring implicit and explicit knowledge of a second language: A psychometric study. Studies in Second Language Acquisition, 27, 141-172. doi:10.1017/S0272263105050096

Folse, K. S., Muchmore-Vokoun, A., \& Solomon, E. V. (2005). Great sentences for great paragraphs (2nd ed.). Boston, MA: Heinle Cengage Learning.

Fotos, S. (2001). Cognitive approaches to grammar instruction. In M. Celce-Murcia (Ed.), Teaching English as a second language (3rd ed., pp. 267-283). Boston: Heinle \& Heinle.

Goh, G. Y. (2007). How authentic is the language of Korean middle school English textbooks? A corpus-based analysis. Korean Journal of English Language and Linguistics, 7, 191-210.

Goldschneider, J., \& DeKeyser, R. (2005). Explaining the "natural order of L2 morpheme acquisition" in English: A meta-analysis of multiple determinants, Language Learning, 55, 27-77.

James, S., \& Khan, L. M. (1982). Grammatical morpheme acquisition: An approximately invariant order? Journal of Psycholinguistic Research, 11, 381-388. doi:10.1007/BF01067588

Johnston, M. (1985). Syntactic and morphological progressions in learner English. Canberra: Commonwealth Department of Immigration and Ethnic Affairs. 


\section{A. D. SCHENCK, W. CHOI}

Johnston, M. (1994). Second language acquisition: A classroom perspective. Australian studies in language acquisition No. 1. ERIC database. (ED411701)

Kim, S. S. (2002). A corpus-based analysis of the words in the elementary school English textbooks. English Teaching, 57, 253-277.

Krashen, S. D., \& Terrell, T. D. (1983). The natural approach. New York: Alemany Press.

Kwon, E. Y. (2004). The comparative fallacy: An analysis and discussion of selected research. Columbia University Working Papers in TESOL \& Applied Linguistics, 4, 1-6.

Krashen, S., Butler, J., Birnbaum, R., \& Robertson, J. (1978). Two studies in language acquisition and language learning. ITL: Review of Applied Linguistics, 39-40, 73-92.

Luk, Z. P.-S., \& Shirai, Y. (2009). Is the acquisition order of grammatical morphemes impervious to L1 knowledge? Evidence from the acquisition of plural -s, articles, and possessive 's. Language Learning, 59, 721-754. doi:10.1111/j.1467-9922.2009.00524.x

Makino, T. (1979). English morpheme acquisition order of Japanese secondary school students. Doctoral Dissertation, ProQuest Dissertations and Theses database. (AAT 8228138)

Mitchell, R., \& Myles, F. (2004). Second language learning theories (2nd ed.). London: Hodder Arnold.

Nekrasova, T. (2009). English L1 and L2 speaker's knowledge of lexical bundles. Language Learning, 59, 647-686. doi:10.1111/j.1467-9922.2009.00520.x

Pienemann, M. (1995). Second language acquisition: A first introducetion. ASLA Australian studies in language acquisition No. 2. ERIC database. (ED425637)

Pienemann, M. (1999). Language processing and second-language development: Processability theory. Amsterdam: John Benjamins Pub- lishing Company.

Pienemann, M. (2005). Cross-linguistic aspects of processability theory. Amsterdam: John Benjamins Publishing Company.

Pienemann, M. (2008). Language processing capacity. In C. J. Doughty, \& M. H. Long (Eds.), The handbook of second language acquisition (pp. 679-714). Oxford: Blackwell Publishing Ltd. doi:10.1002/9780470756492.ch20

Pienemann, M., Di Biase, B., \& Kawaguchi, S. (2005). Extending processability theory. In M. Pienemann (Ed.), Cross-linguistic aspects of processability theory (199-251). New York: John Benjamins.

Schenck, A. (2012). Examining the influence of multiple factors on acquisition order in a South Korean EFL context: A pilot study. Manuscript Submitted for Publication. doi:10.4236/ojml.2012.23015

Schenck, A., \& Choi, W. K. (2012). Taking the guesswork out of curriculum design: Learning to engineer explicit grammar curricula through the analysis of multiple influences on the acquisition process. Open Journal of Modern Linguistics, 2, 114-124.

Schenck, A., \& Lee, C. I. (2009). Evaluating the application of SLA research to explicit grammar lessons within EFL textbooks. Journal of the Modern Linguistic Society of Korea, 25, 1-25.

Spada, N., \& Tomita, Y. (2010). Interactions between type of instruction and type of language feature: A meta-analysis. Language Learning, 60, 263-308. doi:10.1111/j.1467-9922.2010.00562.x

Yang, H. (2008). On teaching strategies in second language acquisition. US-China Education Review, 5, 61-67.

Yavas, M. (2010). Applied English phonology. Malden, MA: Blackwell Publishing. 


\section{A. D. SCHENCK, W. CHOI}

\section{Appendix A}

Table A1.

Stages of multiple morphosyntactic models.

\begin{tabular}{|c|c|c|}
\hline Stage & $\begin{array}{l}\text { Processability Model } \\
\text { Pienemann (1999) \& Johnston (1985) }\end{array}$ & $\begin{array}{l}\text { Natural Order Hypothesis } \\
\text { Krashen \& Terrell (1983) }\end{array}$ \\
\hline 1 & Single Words & $\begin{array}{l}\text { Progressive (-ing) } \\
\text { Plural (-s) } \\
\text { Copula (to be) }\end{array}$ \\
\hline 2 & $\begin{array}{c}\text { SVO } \\
\text { Plural (-s) }\end{array}$ & $\begin{array}{l}\text { Singular Auxiliary (is) } \\
\quad \text { Article }(a, \text { the })\end{array}$ \\
\hline 3 & $\begin{array}{c}\text { Negative }+ \text { Verb } \\
\text { Do Fronting (Do Question Inversion) } \\
\text { (only the "do" auxiliary in present tense is included) } \\
\text { Topicalization } \\
\text { Adverb Fronting }\end{array}$ & Past Irregular \\
\hline 4 & $\begin{array}{c}\text { Y/N Question Inversion } \\
\text { (all auxiliary verbs except do included) } \\
\text { Particle Verb Separation } \\
\text { Wh Copula Inversion } \\
\text { (only present copula is included) }\end{array}$ & $\begin{array}{c}\text { Regular Past } \\
\text { Third Person Singular (-s) } \\
\text { Possessive ('s) }\end{array}$ \\
\hline 5 & $\begin{array}{c}\text { Wh-questions with Auxiliary } \\
\text { (all auxiliary verbs except do included) } \\
\text { Third person singular (-s) }\end{array}$ & \\
\hline 6 & Cancel Inversion & \\
\hline
\end{tabular}

\section{Appendix B}

Table B1.

Grammar type and evaluation criteria in the instrument.

\begin{tabular}{ll}
\hline \multicolumn{1}{c}{ Grammar Type } & \multicolumn{1}{c}{ Evaluation Criteria } \\
\hline 1. Plural (-s, -es) & Correct/Misformed/Absent \\
2. Copula (is, are, 's, " $r$ ") & Correct/Misformed/Absent \\
3. Progressive (-ing) & Correct/Misformed/Absent \\
4. Progressive Auxiliary (is, are, 's, " $r$ ") & Correct/Misformed/Absent \\
5. Past Regular & Correct/Misformed/Absent \\
6. Past Irregular & Correct/Misformed/Absent \\
7. Possessive ('s) & Correct/Misformed/Absent \\
8. Third Person Singular & Correct/Misformed/Absent \\
9. Article ( $a$, an, the) & Correct/Misformed/Absent \\
10. Particle Verbs (particle movement) & Correct/Misformed/Absent \\
11. Negation + Verb & Correct/Misformed/Absent \\
12. Do-fronting & Correct/Misformed/Absent \\
13. Yes/No Inversion & Correct/Misformed/Absent \\
14. Wh Copula Inversion & Correct/Misformed/Absent \\
15. Wh Auxiliary Inversion & Correct/Misformed/Absent \\
16. Cancel Inversion & Correct/Misformed/Absent \\
\hline
\end{tabular}




\section{Appendix C}

Section 1: You (Questions about You).

1. [Past Tense]

Tell me about a fun trip you took (a place you traveled to) (Four sentences).

2. [Cancel Inversion/Inversion]

Students are told they are in the supermarket but can't find any ice cream. They need to ask someone politely where the milk is.

How can you ask someone politely to find out where the milk is?

Section 2: Describe This Room Students view an image of a room and describe it (Image Source: Folse, Muchmore-Vokoun, \& Solomon, 2005: p. 76).

1. [Copula/Plurals/Articles]

This looks a lot like my living room at home. Describe this room (Four sentences).

2. [Separable Particle]

What chores do you (or your mom) do each week to keep the house clean? (e.g. hang your clothes up after taking them off, take the trash out) (Four sentences)

Section 3: Questions for Matt (Students are shown a picture of a person named Matt). They will be told that they will meet him in person. A survey will be provided and students will be prompted to ask questions to get the information included within it. Provided sentences are incomplete, reducing the chance that students will use existing grammatical forms to construct written output.

1. [Aux Inversion]

can swim

2. [Do-Fronting]

wants to go to China

3. [Aux Inversion ]

is taking an English class

4. [Aux Inversion ]

handed a report in last week to his professor $\quad$ Yes/No

5. [Aux Inversion ]

has eaten Mexican food

6. [Cancel Inversion/Do-Fronting]

knows what his wife's favorite color is

Yes/No

7. [Cancel Inversion/Do-Fronting]

found out where his wallet is (he lost it last week) Yes/No

8. [Aux Inversion]

would like to climb a mountain

9. [Do-Fronting]

throws his garbage out more than once a week

10. [Do-Fronting]

needs to save more money

11. [Do-Fronting, Cancel Inversion]

knows the capital of South Korea

12. [Wh-Copula Inversion]

favorite sport

13. [Wh Aux]

can

14. [Wh-Copula Inversion]

happy with his life because

15. [Wh Aux]

grew up in

16. [Wh Aux]

has lived in New York for

17. [Wh Aux]
Is taking a class.

18. [Wh-Copula Inversion]

nationality

19. [Wh Aux]

would like to see the movie

20. [Wh Aux]

If he could have any job, he would be

21. [Wh-Copula Inversion]

favorite food.

Section 4: Your Best Friend Students describe their friend.

1. [Possessive/Copula]

What's your friend's name?

What do you do when you get together?

2. [Third Person Singular]

What does your best friend like?

3. [Present Progressive]

What do you think she is doing right now?

4. [Third Person Singular]

Where does she/he live?

5. [Third Person Singular]

What does she study/do?

Section 5: Family A family tree will be presented. Participants will then be asked the following questions about the chosen individuals.

1. [Copula/Possessive]

Who is Maggie?

Who is Mona?

Who is Herb?

Who is Ling?

[Plural]

How many sisters does Marge have?

Section 6: CASL Questions Students will be shown several images from the CASL test (Carrow-Woolfolk, 1999). They will then be prompted to write according to spoken directions of the test administrator.

1. CASL Picture 1 (Two pictures each having a different sized ball): [Copula IS/Article]

Here is a little ball.

(Point to other picture) Here is (e.g., "a big ball").

2. CASL Picture 3 (Shows two different dogs): [Copula IS]

This dog is little.

(Point to other picture) This dog (e.g., "is big").

3. CASL Picture 6 (Shows two different actions): [Present Progressive IS/Article]

Here the girl is drinking.

(Point to other picture) Here eating a hamburger").

4. CASL Picture 8 (Shows two different actions): [Present Progressive ARE/Plural]

These boys are swimming.

(Point to other picture) These (e.g., "boys are riding bikes").

5. CASL Picture 9 (Shows two different actions): [Present Progressive IS/Article]

Here the dog is barking.

(Point to other picture) Here (e.g., "the dog is sleeping").

6. CASL Picture 13 (Shows a crying baby): [Past Tense]

When the baby fell down, what did he do? (e.g., "He cried for his mom").

$\overline{7 .}$ CASL Picture 14 (Shows two different actions): [Present 


\section{A. D. SCHENCK, W. CHOI}

Progressive ARE/Plural]

Here the birds are eating.

(e.g., "Here the birds are flying").

8. CASL Picture 17 (Shows two pictures with/without a ball): [Negation]

Is there a ball on this table?

(e.g., "No, there isn't").

9. CASL Picture 18 (Shows a four picture narrative sequence): [Past Tense]

Ellen played outside. (Point to next pictures and prompt students).

(e.g., Ellen played outside). (e.g., Her mother called her for dinner).

(e.g., Ellen went inside).

(e.g., She ate dinner/She ate supper).

10. CASL Picture 19 (Shows mother and son): [Negation]

Mother: You lied to me. I know you were smoking.

Son: No, (e.g., "I didn't. I didn't smoke").

11. CASL Picture 22 (Shows woman talking to a man): [Negation]

Will you please have dinner with me?

No,

(e.g., "No, I won't. I don't like

\section{Appendix D}

Table D1.

Multiple regression correlation of EFL acquisition to six causes.

\begin{tabular}{ccccc}
\hline Model & $\mathrm{R}$ & $\mathrm{R}$ Square & Adjusted R Square & Std. Error of the Estimate \\
\hline 1 & .773 & .597 & .328 & 24.03776 \\
\hline
\end{tabular}

Table D2.

Independent variables of multiple regression formula.

\begin{tabular}{|c|c|c|c|c|c|c|}
\hline & \multirow{2}{*}{ Model } & \multicolumn{2}{|c|}{ Unstandardized Coefficients } & \multirow{2}{*}{$\begin{array}{c}\text { Standardized Coefficients } \\
\text { Beta }\end{array}$} & \multirow{2}{*}{$\mathrm{t}$} & \multirow{2}{*}{ Sig. } \\
\hline & & B & Std. Error & & & \\
\hline \multirow{7}{*}{1} & (Constant) & 64.997 & 29.472 & & 2.205 & .055 \\
\hline & Frequency in EFL Context & .021 & .020 & .243 & 1.081 & .308 \\
\hline & L1 Similarity & 12.599 & 8.941 & .368 & 1.409 & .192 \\
\hline & Morphosyntactic Alternations & -.025 & .023 & -.404 & -1.097 & .301 \\
\hline & Semantic Complexity & -2.872 & 6.745 & -.171 & -.426 & .680 \\
\hline & Sonority & .372 & .616 & .288 & .604 & .561 \\
\hline & Morphosyntactic Complexity & -4.864 & 6.359 & -.197 & -.765 & .464 \\
\hline
\end{tabular}

